\title{
A PROCEDURE FOR COMPARING THE EFFICACY OF INSECTICIDES FOR GREENHOUSE WHITEFLY CONTROL
}

\author{
N.A. MARTIN and P.J. WORKMAN \\ New Zealand Institute for Crop \& Food Research Ltd, \\ Private Bag 92169, Auckland
}

\begin{abstract}
Five insecticides, tau-fluvalinate (96 mg/litre), imidacloprid ( 50 , 100 or $150 \mathrm{mg} /$ litre) and three "organic" insecticides YR55 (1.2 g/litre), YR65 (1 ml/litre) and YR70 (3.6 g/litre), as well as water control were applied three times (10 and 8 days apart) to Mexican sun flower plants (Tithonia rotundifolia). Each plant had four tagged leaves infested with either eggs, first instar nymphs, third instar nymphs or puparia of greenhouse whitefly (Trialeurodes vaporariorum). Mortality was assessed after whitefly passed to the next growth stage. YR55 gave poor control of all whitefly stages while YR70 gave moderate control of all stages. The other insecticides gave good control when leaves were initially infested with eggs and first instar nymphs. Imidacloprid and YR65 gave better control of whitefly than tau-fluvalinate where leaves were initially infested with third instar nymphs and puparia. Tagged leaves infested with cohorts of juvenile whitefly provided an efficient method to assess the efficacy of the pesticides.

Keywords: Greenhouse whitefly, Trialeurodes vaporariorum, juvenile stages, insecticide efficacy.
\end{abstract}

\section{INTRODUCTION}

Whitefly are serious pests of several greenhouse vegetable and ornamental crops (Byrne et al. 1990). Biological control of greenhouse whitefly, Trialeurodes vaporariorum (Westwood) (Hemiptera: Aleyrodidae) has been increasingly successful (Lenteren 1995), but there is still a need for insecticides, especially for ornamental crops where integrated pest management can be difficult to implement. Whitefly have several life stages, including eggs and puparia, which may be resistant to many insecticides, and even the different nymphal stages and the adults can vary in susceptibility to an insecticide. The effect of an insecticide treatment on each life stage should be assessed as well as the overall impact on the population in order to develop the best use pattern for the chemical. The senior author has seen many unpublished reports on efficacy of insecticides for whitefly control which only assessed the effect of sprays on adult whitefly populations, the easiest stage to assess. This gives a misleading impression of the efficacy of an insecticide. A cluster of two to three applications of an insecticide is generally required to kill most individuals of a generation (Martin 1996).

Whitefly biology can be exploited to make small plot insecticide trials more efficient. Female greenhouse whitefly prefer to feed and lay eggs on young plant leaves and the females keep moving onto new leaves as plants grow. Because juvenile whitefly stay on the leaves on which eggs were laid, it is possible to have cohorts of different juvenile stages on separate leaves of the same plant. Based on this, we developed a procedure that allows the assessment of insecticide treatments on all juvenile stages of whitefly in a single trial (Martin and Workman 1984). The present paper describes how this procedure was used to compare the efficacy of five insecticides for whitefly control on home garden ornamental plants, when each was applied as a cluster of three sprays. 


\section{Plants}

\section{MATERIALS AND METHODS}

Mexican sunflower, Tithonia rotundifolia (Asteraceae), were grown from seed and planted one per pot (100 mm diameter). Plants were kept in a greenhouse and after transfer to $150 \mathrm{~mm}$ diameter pots, each plant was restricted to a single stem by pruning side shoots. Flower buds were removed.

\section{Whitefly}

Adult greenhouse whitefly reared on tobacco plants by BioForce Ltd, (South Auckland) were released onto the plants three times (22 and 29 April, 13 May 1998). Voucher specimens of these adult whitefly and puparia have been deposited in the National Arthropod Collection, Mount Albert Research Centre, Auckland.

\section{Treatments}

Immediately prior to the first pesticide application (19 May) four leaves on each plant were selected. Leaves with eggs, first instar, third instar and puparia were tagged and the developmental stage of the whitefly was recorded. Sixteen plants were allocated to each of the eight treatments with two plants/plot, giving eight replicates.

The insecticides (Table 1) were applied on 19 May, 29 May and 6 June 1998. Plants were individually sprayed to run off using a hand-pumped Cambrian sprayer of the kind used by home gardeners. When the plants were dry, they were returned to the greenhouse and arranged in one of eight metal trays, one tray per replicate. The 16 plants (two pots x eight treatments) were arranged randomly on each tray.

\section{Assessments}

The numbers of live and dead adult whitefly on the top four leaves of each plant were counted 2 days after the first spray. These were not the four tagged leaves.

After the third spray, mortality of juvenile whitefly was assessed when live whitefly on the tagged leaves had passed to the next growth stage. In each plot the best quality of the two tagged leaves of each growth stage per plot were selected and picked just prior to assessment. Leaves were examined under a stereo microscope and the numbers of live and dead insects of each growth stage were recorded. Depending on the number of whitefly present, one-quarter, one-half or the whole leaf was examined. Where only part of a leaf was examined, at least 50 whitefly were assessed.

Depending on the whitefly stage on a leaf when it was first sprayed, the dead and live whitefly of each life stage were allocated to one of three categories: "alive", surviving treatment; "dead", died after treatment; and "from eggs laid after treatments were applied". For example, on leaves where only eggs were present at the first spray, the "alive" category included live $2^{\text {nd }}, 3^{\text {rd }}$ and $4^{\text {th }}$ instar nymphs, live puparia and empty puparia; the dead category included dead $1^{\text {st }}, 2^{\text {nd }}, 3^{\text {rd }}$ and $4^{\text {th }}$ instar nymphs, dead puparia and adults dying during emergence; the "from eggs laid after treatment" category" included white and black eggs and live $1^{\text {st }}$ instar nymphs.

\section{Data analysis}

The total number of dead juvenile whitefly after treatment was analysed as a percentage of the total using logistic regression (McCullagh and Nelder 1989). The method used for testing treatments was analogous to analysis of variance for an equivalent randomised block experiment. The percent dead was predicted for each treatment after adjustment for replicate differences. Analysis was carried out using Genstat 5 (Genstat Committee 1998).

\section{RESULTS}

The numbers of live and dead adult whitefly on plants two days after the first spray are shown in Table 1. The unanalysed data suggests that YR65 caused high mortality and that YR70 and tau-fluvalinate may have reduced the numbers of live adult whitefly. Mortality of whitefly first treated as eggs, first instar, third instar and puparia was least $(\mathrm{P}>0.05)$ on control plants (Table 1).

YR55 gave poor control of whitefly when any stage was present at first treatment. Mortality was less on YR55-treated plants than on plants treated with other insecticides except tau-fluvalinate-treated plants first treated when third instar nymph and puparia 
were present and imidacloprid (50 $\mathrm{mg} /$ litre)-treated plants first treated when puparia were present.

TABLE 1: The effect of a single insecticide spray on adult whitefly and three insecticide applications on juvenile whitefly. Live and dead whitefly adults on the top four leaves of each plant 2 days after first spray pesticide application. Sixteen plants/treatment were examined. Mean percent mortality of whitefly after treatment with three applications of pesticide. $95 \%$ confidence limits in brackets.

\begin{tabular}{lcccccc}
\hline \multirow{2}{*}{ Treatment } & \multicolumn{3}{c}{ Adult whitefly } & \multicolumn{3}{c}{ Juvenile stage treated } \\
& Live & Dead & Eggs & 1st instar & 3rd instar & Puparia \\
& & & & nymphs & nymphs & \\
\hline Water control & 126 & 0 & 0.50 & 0.24 & 0.60 & 0.35 \\
& & & $(0.07,3.34)$ & $(0.03,1.7)$ & $(0.11,3.3)$ & $(0.02,6.0)$ \\
Imidacloprid ${ }^{1} 50 \mathrm{mg} /$ litre & 42 & 2 & 97 & 98 & 85 & 8.7 \\
& & & $(91,99)$ & $(93,99)$ & $(76,91)$ & $(4.3,17)$ \\
Imidacloprid 1 100 mg/litre & 110 & 23 & 97 & 99 & 84 & 23 \\
& & & $(90,99)$ & $(95,99.8)$ & $(72,91)$ & $(14,34)$ \\
Imidacloprid $150 \mathrm{mg} /$ litre & 77 & 33 & 99.8 & 99.8 & 82 & 27 \\
& & & $(92,100)$ & $(91,100)$ & $(69,90)$ & $(17,40)$ \\
Tau-fluvalinate $296 \mathrm{mg} / \mathrm{litre}$ & 28 & 1 & 93 & 91 & 22 & 3.9 \\
& & & $(84,97)$ & $(84,94)$ & $(14,31)$ & $(1.0,14)$ \\
YR55 1.2 g/litre & 76 & 33 & 49 & 30 & 23 & 8.0 \\
& & & $(38,60)$ & $(23,38)$ & $(17,31)$ & $(4.0,15)$ \\
YR70 3.6 ml/litre & 16 & 1 & 84 & 87 & 78 & 52 \\
& & & $(74,91)$ & $(81,92)$ & $(68,86)$ & $(40,63)$ \\
YR65 1 ml/litre & 7 & 2 & 95 & 99 & 88 & 62 \\
& & & $(84,98)$ & $(95,100)$ & $(78,94)$ & $(50,72)$ \\
\hline
\end{tabular}

${ }^{1}$ As Confidor (50 g imidacloprid/kg)

${ }^{2}$ As Mavrik (9.6 g tau-fluvalinate/litre)

YR65 gave good control of all whitefly stages compared to other insecticides, though mortality was less for whitefly first treated as third instar nymphs and puparia than when first treated as eggs and first instar nymphs. Mortality of whitefly first treated as puparia on YR70 and YR65-treated plants was greater than on all other treated plants.

YR70 gave moderate control of whitefly when they were first treated at all stages. Mortality was less on YR70-treated plants than on imidacloprid-treated plants when the insects were first treated as eggs and first instars.

The industry standard insecticide, tau-fluvalinate, gave good control of whitefly when they were first treated as eggs and first instars but killed few whitefly when they were first treated as third instars and puparia.

Imidacloprid gave equal or better control of whitefly than tau-fluvalinate. It was more effective than tau-fluvalinate on whitefly first treated as third instar and puparia. The lowest concentration of imidacloprid $(50 \mathrm{mg} / \mathrm{litre})$ was less effective than the other two concentrations when first applied to puparia.

\section{DISCUSSION}

The technique of assessing the effect of insecticide treatments on all stages of whitefly showed the strengths and weaknesses of each product and differentiated between the concentrations of imidacloprid. For example, tau-fluvalinate gave good control of whitefly when they were first treated as eggs and first instar but poor control when they were first treated at later stages, while YR65 gave relatively good control of all whitefly stages. The apparent good control of whitefly by some products when 
they were first treated as eggs was probably due to mortality of first instar nymphs rather than direct mortality of eggs, with the pesticide killing the first instars as residues, direct spray or both. To distinguish between these effects and to assess more completely the efficacy of the insecticides it would be desirable to determine the effect of a single application as well as a cluster of sprays.

The assessment of adult whitefly on plants after the first insecticide spray suggested that the insecticides varied in their effect on this stage, but redistribution of adult whitefly between plants in the small plots meant further observations would not be meaningful. Where small plots of two to four plants are used and plants may be continually re-infested, it is not possible to assess the long-term efficacy of the treatments. Long term assessment would require the use of either very large plots or ideally separate greenhouse compartments for each treatment.

Mexican sunflower plants grew well in pots and provided a suitable host for greenhouse whitefly without becoming too large. In the greenhouse, plants were susceptible to thrips and aphids, which are not normally seen on outdoor plants. Also suitable for this type of trial are greenhouse cucumbers, a fast-growing vegetable, which can be grown as a single shoot two metres high (N. Martin unpubl.data).

\section{CONCLUSION}

When applied as a cluster of three sprays about ten days apart, both YR65 and imidacloprid gave better control of greenhouse whitefly than the standard insecticide, tau-fluvalinate. The assessment of the effect of the insecticides on cohorts of juvenile whitefly on tagged leaves provided an efficient technique for comparing the efficacy of insecticides. It would be useful to assess the effect of a single spray as well as a cluster of three sprays. These small scale trials should be followed by experiments where re-infestation of treated plants from water-treated plants is prevented.

\section{ACKNOWLEDGEMENTS}

Ruth Butler (Crop \& Food Research) for statistical analysis and constructive comment; Madhu Madhusudhan for technical assistance. Yates NZ Ltd funded this trial.

\section{REFERENCES}

Genstat Committee, 1998. Genstat 5 Release 4.1 Reference Manual Supplement. $\mathrm{NaG}$, Oxford, UK. 229 pp

Bryne, D.N., Bellows, T.S. and Parrella, M.P., 1990. Whiteflies in agricultural systems. Pp. 227-261. In: Whiteflies: their Bionomics, Pest status and Management. Gerling, D. (Ed) Intercept, Andover, UK.

Lenteren, J.C. van, 1995. Integrated pest management in protected crops. Pp. 311-343. In: Integrated Pest Management. Dent, D. (Ed) Chapman and Hall, London.

Martin, N.A., 1996. Whitefly insecticide resistance management strategy. Pp. 194203. In: Pesticide Resistance: Prevention and Management. Bourdôt, G.W. and Suckling, D.M. (Eds). New Zealand Plant Protection Society Inc, Lincoln, Canterbury, NZ.

Martin, N.A. and Workman, P.J., 1984. Control of greenhouse whitefly with oxamyl grannules. Proc. 37th N.Z. Weed and Pest Control Conf:: 265-267.

McCullagh, P. and Nelder, J.A., 1989. Generalised Linear Models ( $2^{\text {nd }}$ edition). Chapman and Hall, London. 